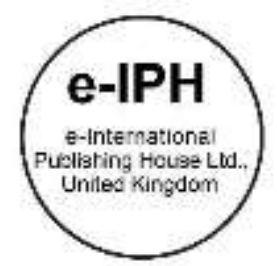

\title{
Mobile Phone Addiction: Determinant factors among students in a Malaysian public university
}

\author{
Chan Yuen Fook, Suthagar Narasuman \\ Faculty of Education, Universiti Teknologi MARA \\ FSK 1, 5 Building, UiTM Puncak Alam Campus \\ 42300 Puncak Alam, Selangor, Malaysia \\ yuenfook@uitm.edu.my, suthagar@uitm.edu.my \\ Tel of 1st Author: +603-32584941
}

\begin{abstract}
The present study was conducted to examine mobile addiction determinant factors among university students in higher education in Malaysia. A total of 162 students responded to the online survey questionnaire. The study employed a quantitative-based research method to obtain data, and the research instruments consist of a set of combined questionnaires adopted from two Ph.D. studies. The correlation result between mobile addiction and attitude showed a stronger association than with the purpose of use. However, linear regression only indicated a significant contribution of students' attitude towards mobile addiction variance.
\end{abstract}

Keywords: Attitude; Mobile addiction; Purpose of Use: University students

eISSN: 2398-42870 2021. The Authors. Published for AMER ABRA cE-Bs by e-International Publishing House, Ltd., UK. This is an open access article under the CC BYNC-ND license (http://creativecommons.org/licenses/by-nc-nd/4.0/). Peer-review under responsibility of AMER (Association of Malaysian Environment-Behaviour Researchers), ABRA (Association of Behavioural Researchers on Asians/Africans/Arabians) and CE-Bs (Centre for Environment-Behaviour Studies), Faculty of Architecture, Planning \& Surveying, Universiti Teknologi MARA, Malaysia..

DOI: https://doi.org/10.21834/ebpj.v6iSI4.2905

\subsection{Introduction}

Before the invention of mobile devices, behavioral addictions among adolescents was often closely related to work (Andreassen, Hetland \& Pallesen, 2010), video games (Fisher, 1994), exercise (Adam \& Kirkby, 2002), shopping (Igarashi, Motoyoshi, Takai \& Yoshida, 2008), food (Oxford, 2001) and internet (Young \& de Abreu, 2011). Initially, the term addiction was used in the medical field to refer to high dependence on a substance such as alcohol or drugs (Bianchi \& Phillips, 2005). Lately, the term is broadly used in many areas such as compulsive excessive engagement behaviors (gaming, shopping) (Lemon, 2002). Dedyukhina (2016) has found that smartphone notifications drive people to repeatedly look into their devices until their behavior becomes automatic and unconscious. She concluded that this technology was designed on purpose to make people use it repetitively. From a medical perspective, Yu and Sussman (2020) maintain that it may not be a real addiction as the ethiopathological pathways and processes are yet to be identified but agree that widespread and pervasive use of smartphones has resulted in a host of medical and social problems such as blurred vision, sleep disturbances, distracted driving and, poor academic performance. People have become dependent on their smartphones because they have outsourced too many applications to them. Scudamoe (2018) claimed that there are many functions of smartphones such as GPS, cameras, gaming consoles, health trackers, and many other applications people tend to rely on other than just limit to communication. These apps are now part and parcel of day to day life. For young people in educational institutions, it has become the number one gadget to access information ranging from academic knowledge to sports and entertainment in an environment where the use of

eISSN: 2398-4287C 2021. The Authors. Published for AMER ABRA cE-Bs by e-International Publishing House, Ltd., UK. This is an open access article under the CC BYNC-ND license (http://creativecommons.org/licenses/by-nc-nd/4.0/). Peer-review under responsibility of AMER (Association of Malaysian Environment-Behaviour Researchers), ABRA (Association of Behavioural Researchers on Asians/Africans/Arabians) and cE-Bs (Centre for Environment-Behaviour Studies), Faculty of Architecture, Planning \& Surveying, Universiti Teknologi MARA, Malaysia..

DOI: https://doi.org/10.21834/ebpj.v6iSI4.2905 
smartphones has gained a high level of social acceptance (Obi, Omoregie, Onoriose, 2020) The theory of psychological ownership (Pierce et al., 2003) predicts a significant and positive relationship between the object and psychological ownership. Common Sense Media (2016), a non-profit group based in California, USA, which was developed to help children, parents, teachers, and policy-makers, has urged more studies to determine technology addiction, its signs, and its consequences. Some studies have established a relationship between mobile addiction and attitude in various aspects. For instance, Thomee et al. (2011) state that frequent use of mobile phones is associated with stress, sleep disturbances, and symptoms of depression among youngsters. A study by Roberts et al. (2015) found that depressed individuals were more addicted to their mobile phones than those with emotional stability. Besides, there was also a study found individuals who are prone to use mobile phones are often those who want to reduce their feelings of discomfort from social interactions (Lee et al., 2014), even though other studies have shown a positive social interaction with the use of mobile phones (Kim, Lee \& Kim, 2014). For students, emotional stability and kindling good relationships with peers and teachers determine factors that lead to higher academic achievement. Murphey (1996) admits that addiction to mobile phones among adolescent students can cause undesired academic behavior (Haruna et al., 2016). Instead of concentrating on their homework, these adolescent students spent more time on mobile phones during lectures leading to lower grades and poor academic achievement (Sundari, 2015: Haruna et al., 2016). Recently, there was a study which also found strong relationships between musculoskeletal complications, variant sleep disorders, and smartphone addiction among students, leading to health issues and low academic performance (Alkhateeb, Alboali, Alharbi, Saleh, 2021).

Other than that, several descriptive studies have been conducted on mobile addiction in India and Turkey (Goswami \& Singh, 2016; Ozkan \& Solmaz, 2015). There were also studies conducted at the school level in Nigeria (Haruna et al., 2016) and college level in India to check on mobile phone use and how it affects academic performance by focusing on learning achievement by mobile phone use. Both studies were very descriptive but lacked adequate discussion in demonstrating mobile addiction's effect on academic behavior. Research on mobile phones effect on academic behavior in higher education has not been given much attention (Ling 2004). Nevertheless, one study was conducted in South Korea to verify mobile phone dependency and its impacts on adolescents' social and academic behavior (Seo, Park, Kim \& Park, 2016). There are also a few studies that have been conducted to identify the determinant factors of mobile addiction based on gender. For example, Tangmunkongvorakul, Musumari, Tsubohara, Ayood Srithanaviboonchai and Techasrivichien (2020) have identified female students as having a higher risk of smartphone addiction than male students. This is consistent with findings from a previous study on smartphone addiction and, overuse among adolescents and young people in Korea (Lee \& Lee, 2017). Besides, there were two studies have been conducted to identify age, and purpose of use as predictors for mobile addiction (Lee \& Lee, 2017; Cheung, Lee, Tse, Do, So, Szeto, 2019). However, these findings are still indecisive. Thus, there is a need to conduct more studies to identify the determinant factors of mobile phone addiction among university students in Malaysian context. Hence, two research questions have been crafted as follow:

1. Is there a significant relationship between mobile addiction, attitude, and purpose of use among university students?

2. What are the determining factors (attitude, age, the purpose of use) towards the variance in mobile addiction among university students?

\subsection{Methodology}

This study employed a correlational research design to investigate the influence of gender, age, attitude, and purpose of mobile addiction among university students. A quantitative research method was selected to test and confirm the hypotheses made, and it is the best method to collect information to demonstrate relationships and describe it as it exists. Thus, this approach allows research variables to be quantified and analyzed with statistical procedures (Haruna et al., 2016). This study has employed a case study approach at the Faculty of Education of the biggest public university in Malaysia, Universiti Teknologi MARA. These respondents were selected randomly from two major undergraduate programs namely, B. A. (Hons). TESL and B. A (Hons). Physical Education. The decision to select the undergraduates from these two programs from Semester 1 to 4 students is because younger groups face more mobile use issues than their seniors (The Star, 2019). These two programs were selected because they are the two major programs at the undergraduate level that represent the student population. Table 1 states the details of the selection of samples from these two major programs.

Table1 Selection of respondents for the study

\begin{tabular}{l|l|l}
\hline Program & Population & Sample \\
\hline B. A. (Hons). TESL & 168 & 84 \\
(Semester 1 -4) & 156 & 78 \\
$\begin{array}{l}\text { B. A. (Hons). Physical Education } \\
\text { (Semester 1 - 4) }\end{array}$ & 324 & 162 \\
\hline Total & & \\
\hline
\end{tabular}

A total of 84 students were selected randomly from the B. A (Hons) TESL Program and another 78 students were selected randomly from the Physical Education Program to participate in this survey. Finally, 162 undergraduate students from semester 1 to 4 were selected to respond to the online survey questionnaire. The data was collected during the academic term of the semester from September to December 2019. The respondents are allowed to answer the survey questionnaire on their own free time because this is an online Google Form. The present study employed a quantitative research method to obtain and analyze research data. The research 
instruments used to glean data consist of a set of combined questionnaires adopted from two instruments, namely Laramie's (2007) study on Emotional and Behavioural Aspects of Mobile Phone Use at Alliant International University, Los Angeles, California, and another instrument from Valderrama (2014) entitled "Development and Validation of the Problematic Smartphone Use Scale." As a whole, the instrument consists of four parts - Part A (Mobile addiction) consists of 19 items, Part B (Attitude Scale) consists of 18 items, Part C (Purpose of use) consists of 13 items, and Part D (Demographics and open-ended question). Regarding data analysis, the variables of mobile addiction, attitude, and purpose of use were computed before correlation, and multiple regression analysis was conducted. The statistical procedure followed this to establish the relationship between the three variables and, identify the determinant factors that induce mobile addiction variance based on the three factors identified. These statistical procedures were conducted using the Pearson Product Moment Correlation and multiple regression analysis. However, the study does have its limitation due to the use of a closedended questionnaire and the involvement of students from only one faculty in a public university. Hence, these limitations will restraint the findings to be generated to all the faculties in the public universities in Malaysia.

\subsection{Findings}

A Pearson Product Moment Correlation has been conducted to answer the first research question as follow: "Is there a significant relationship between mobile addiction, attitude, and purpose of use among university students?

\subsection{Correlations}

Table 1, presents the findings on the relationship between mobile addiction, attitudes, and purpose of use amongst the respondents.

Ho1 = There is no significant correlation between mobile addiction and the attitude scale among the students from the Faculty of Education

$\mathrm{H}_{0} 2=$ There is no significant correlation between mobile addiction and purpose of use among the students from the Faculty of Education

Table 2 Correlation analysis of mobile addiction, attitude scale, and purpose of use

\begin{tabular}{|c|c|c|c|c|}
\hline Correlation & & Mobile addiction & Attitudes Scale & Purpose of Use \\
\hline & Pearson Correlation & 1 & $.688^{*+}$ & .275 \\
\hline \multirow[t]{3}{*}{ Mobile addiction } & Sig. (2-tailed) & & .000 & .066 \\
\hline & $\mathrm{N}$ & 162 & 162 & 162 \\
\hline & Pearson Correlation & $.688^{* *}$ & 1 & $.423^{* *}$ \\
\hline \multirow[t]{3}{*}{ Attitudes } & Sig. (2-tailed) & .000 & & .003 \\
\hline & $\mathrm{N}$ & 162 & 162 & 162 \\
\hline & Pearson Correlation & .275 & $.423^{* *}$ & 1 \\
\hline \multirow[t]{2}{*}{ Purpose of use } & Sig. (2-tailed) & .066 & .003 & \\
\hline & $\mathrm{N}$ & 162 & 162 & 162 \\
\hline
\end{tabular}

$* *$. Correlation is significant at the 0.01 level (2-tailed)

Since Pearson's coefficient showed $\mathrm{r}=.688$, this indicated a positive, moderate, and very significant relationship between mobile addiction and attitude $(r=.688, p=.000)$. Meanwhile, since Pearson's coefficient showed $r=.275$, this indicated a weak and insignificant relationship between mobile addiction and the purpose of use scale $(r=.275, p=.066)$ in Table 2. Based on the hypotheses for correlation, we rejected $\mathrm{Ho} 1$ and accepted $\mathrm{Ho2}$. These findings indicated that there is a moderate relationship between mobile addiction and attitude among students in higher education, however, mobile addiction is not associated with the purpose of use.

\subsection{Multiple Regression}

Multiple Regression analysis was conducted to answer the second research question of "What are the determining factors (attitude, age, the purpose of use) towards the variance in mobile addiction among university students?". This Multiple Regression will identify the significant predictors of mobile addiction that affect the students' academic behavior in higher education. For this purpose, a multiple regression analysis was performed to predict the level of contribution of the three independent variables - attitude, the purpose of mobile phone use, and age towards the dependent variable, mobile addiction.

Ho3: Attitude does not affect mobile addiction among students from the Faculty of Education Ho4: Purpose of Use does not affect mobile addiction among students from the Faculty of Education Ho5: Age does not affect mobile addiction among students from the Faculty of Education

Regression Equation:

$Y=a+b \times 1+c \times 2+d \times 3$

$\mathrm{Y}=$ Mobile addiction 


$$
\begin{aligned}
& a=\text { Regression constant } \\
& b=\text { Attitude scale } \\
& c=\text { Purpose of use } \\
& d=\text { Age } \\
& Y(\text { Mobile Addiction) }=.608+.598 \times \text { (Attitude Scale) }
\end{aligned}
$$

Table 3 also indicates the value of $R^{2}$ and adjusted $R^{2}$. The $R^{2}$ was 0.398 while the adjusted $R^{2}$ was .363 . This means that $39.8 \%$ and $36.3 \%$ of the total variances in the attitude scale was attributed to mobile phone addiction among the respondents. The contribution of the predictor variables towards the variance in this study was reported based on the adjusted $R^{2}$ value because its value could return a better estimation of the true population value. The result of $R^{2}$ indicated every unit increment of attitude of the students will contribute to $36.3 \%$ of the mobile addiction among the undergraduate students at the Faculty of Education. However, the results from Table 3 and the regression equation indicates that the purpose of use (Beta=.034, $p>.01)$ and age of the respondents (Beta=-.137, $p>.01)$ did not contribute to mobile addiction except attitude (Beta=.598, $p<.01)$.

Since the sample size $(n=162)$ is deemed sufficient in this study, hence, the findings may be able to imply to the students at the Faculty of Education in other public universities in Malaysia. In general, the findings suggest that dependence on mobile phones needs to be persistently studied to produce salient and legitimate reports on the latest trends in mobile use among university students. Mobile addiction is a contemporary issue affecting students and therefore, it is necessary to continue investigating other factors that facilitate mobile addiction in a worst-case scenario such as nomophobia (fear of being without a smartphone).

It is also imperative to develop suitable handling and treatment procedures for any case that triggers a negative smartphone impact among the students. Furthermore, it's better to support students in dealing with their mobile addiction with healthy physical and mental activities that help them to achieve their learning goals in class. In the course of their study, the researchers also noticed that most students admit that they checked their phones without any reason. A behavior that is not a new phenomenon but somewhat unpleasant because it may drag or procrastinate them from doing something more important during the day. This is why some people describe mobile addiction as part of mental illness. Many students are known to be unable to use their smartphones wisely leading to detrimental academic performance. Some people even start considering their phone as their best friend and, as a result, lose face time with their real friends, leading to socially awkward situations.

Table 3 Predicting Factors of Mobile Addiction

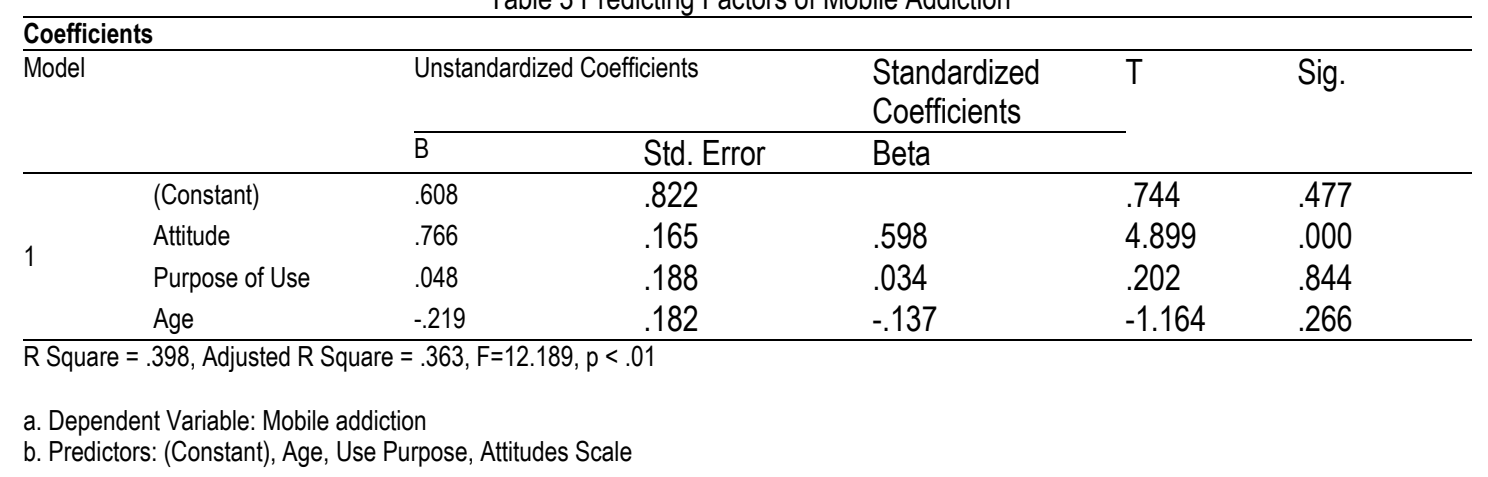

It is not wise to blame the device because it is not the smartphone's problem. The real problem comes down to the behavior of smartphone users. Nevertheless, smartphone users have the option to change their behavior accordingly. Some options suggested are by understanding smartphone etiquette. This would include putting it away during social situations, asking others to put their phone away too, avoid keeping phones on the bedside when sleeping, and turning off notifications. These options may help students to live their life healthier, mentally, physically, socially, and achieve their learning goals.

\subsection{Conclusion and New Directions}

These days, addiction to smartphones and fear of being without a smartphone (nomophobia) is a common global scenario. Mobile addiction has become a problem akin to alcoholism and drug addiction, whereby users cannot detach themselves from their smartphones. Students from higher education have been badly affected in this case. Most students from higher education in this study agreed that smartphones are among the most essential devices in their lives. The respondents acknowledged that smartphones helped them feel better, communicate effectively, and source information at greater speeds because manufacturers constantly upgrade the technology. However, it is also wise to control usage before it escalates into an addiction with detrimental effects on their academic achievement. It can escalate into a problem for themselves and the people around them. One such problem is labeled "phubbing" (a term created by combining the words phone and snubbing). It refers to a person interacting with their phone (or other devices) rather than interacting with a human being. Hence, by understanding the undesirable effects of mobile addiction among students, proper treatment such as conducting smartphone use workshop can focus on the necessary aspects of using smartphones wisely and healthily 
among the undergraduates in higher learning institutes. In the future, the research on mobile addiction can focus on the mediating variable of interpersonal relationship on the relationships between mobile addiction and academic behavior of the adolescents in higher education so that the university administrators will be able to grasp a better understanding on the mobile addiction among young adults in higher education. It is also suggested that future studies could explore the literature on the relationship between mobile addiction, interpersonal relationships, and academic behavior so that we could develop a more convincing conceptual framework for the reference of future researchers. Future studies could also focus on the difference between addiction to the device and addiction to the platforms and applications accessible through the device. Different platforms and applications may exude different levels of addiction. Therefore, it is essential to determine if addiction levels can be scaled down or eradicated by barring access to the most addictive platforms and applications.

\section{Acknowledgments}

This paper is part of an FRGS research project funded by the Ministry of Education, Malaysia and Research Management Centre, Universiti Teknologi MARA, Malaysia [Project Code: 600-IRMI/FRGS 5/3 (027/2019)] Malaysia.

\section{References}

Adams, J. \& Kirkby, R.J. (2002). Excessive exercise as an addiction: A review. Addict Resource Theory, 10, 415-37

Alkhateeb A, Alboali R, Alharbi W, Saleh O. (2020). Smartphone addiction and its complications related to health and daily activities among university students in Saudi Arabia: A multicenter study. J Family Med Prim Care, 9:3220-4.

Andreassen, C.S., Hetland, J. \& Pallesen, S. (2010). The relationship between 'workaholism', basic needs satisfaction at work, and personality. European Journal Personal, 24, 3-17.

Bianchi, A. \& Phillips, J.G. (2005). Psychological predictors of problem mobile phone use. CyberPsychology \& Behavior, 8(1), $39-51$.

Common Sense Media. (2016). New report finds teens feel addicted to their phones, causing tensions at home. Retrieved from https://www.commonsensemedia.org/about-us/news/press- releases/new-report-finds-teens-feel-addicted-to-their-phones-causingtension-at

Cheung T, Lee RLT, Tse ACY, Do CW, So BCL, Szeto GPY, et al. (2019). Psychometric Properties and Demographic Correlates of the Smartphone Addiction ScaleShort Version Among Chinese Children and Adolescents in Hong Kong. Cyberpsychology, behavior and social networking, 22(11):714-23

Dedyukhina A.(2016). Could you live without a smartphone? Anastasia Dedyukhina, TEDxWandsworth. Retrieved from: https://www.youtube.com/watch?v=uNQujCwCu88

Fisher, S. (1994). Identifying video game addiction in children and adolescents. Addict Behavior, 19, 545-53.

Goswami, V. \& Singh, D. R. (2016). Impact of mobile addiction on adolescent's life: A literature review. International Journal of Home Science, 2 (1): $69-74$.

Haruna, R., Aisha, I.M., Yunusa, U. \& Hadiza, T.A. (2016). Impact of mobile phone usage on academic performance among secondary school students in Taraba State Nigeria. European Scientific Journal, 12(1), 466-479.

Igarashi, T., Motoyoshi, T., Takai, J. \& Yoshida, T. (2008). No mobile, no life: Self-perception and text-message dependency among Japanese high school students. Computer-Human Behavior, 24, 2311-2324.

Kim, H., Lee, M. \& Kim, M. (2014). Effects of mobile instant messaging on collaborative learning processes and outcomes: The case of South Korea. Educational Technology \& Society, 17(2), 31-42. Retrieved from http://www.ifets.info

Laramie, D. J. (2007). Emotional and behavioral aspects of mobile phone use. Ph.D. Dissertation. Alliant International University, Los Angeles, California.

Lee C, Lee S-J. (2017). Prevalence and predictors of smartphone addiction proneness among Korean adolescents. Children and Youth Services Review, 77(C):10-7.

Lee, Y.K., Chang, Y., Lin, Y. \& Cheng, Z.H. (2014). The dark side of smartphone usage: Psychological traits, compulsive behavior, and technostress. Computers in Human Behavior,31, 373-383.

Lemon, J. (2002). Can we call behaviors addictive? Clinical Psychologist, 6(2), 44-49.

Ling, R.S. (2004). The mobile connection: The cell phone's impact on society. San Francisco, CA: Morgan Kaufmann Publishers.

Murphey, B. (1996). Computer addictions entangle students. The APA Monitor.

Obi Al, Omoregie MO, Onoriose BO. (2020). Prevalence and determinants of smartphone addiction among undergraduate students in a tertiary educational institution, Nigeria. Nig J Med Dent Educ; 2(2):61-72.

Oxford, J. (2001). Excessive appetites: A psychological view of the addictions (2nd ed.). Chichester, West Sussex, England: Wiley \& Sons.

Ozkan, M., \& Solmaz, B. (2015). Mobile addiction of generation Z and its effects on their social lives. Procedia - Social and Behavioral Sciences, 205, 92-98. 
Pierce, J. L., Kostova, T., \& Dirks, K. T. (2003). The state of psychological ownership: Integrating and extending a century of research. Review of General Psychology, 7(1), 84-107.

Roberts, J.A., Petnji Yaya, L.H. \& Manolis, C.H. (2014). The invisible addiction: cell-phone activities and addiction among male and female college students. Journal of Behaviour Addiction, 3, 254-265.

Tangmunkongvorakul A, Musumari PM, Tsubohara Y, Ayood P, Srithanaviboonchai K, Techasrivichien T, et al. (2020) Factors associated with smartphone addiction: A comparative study between Japanese and Thai high school students. PLoS ONE 15(9): e0238459. https://doi.org/10.1371/journal.pone.0238459

The Star (2019). Phone addiction affects the youngest among us. Retrieved from https://www.thestar.com.my/opinion/letters/2019/07/19/phone-addiction-affects-theyoungest-among-us

Scudamore B. (2018). The truth about mobile addiction, and how to beat It. Retrieved from https://www.forbes.com/sites/brianscudamore/2018/10/30/the-truth-aboutsmartphone- addiction-and-how-to-beat-it/\#5d3f20254232

Seo, D. G., Park, Y., Kim, M. K. \& Park, J. (2016). Mobile phone dependency and its impacts on adolescents' social and academic behaviors. Computers in Human Behavior, 63, 282-292.

Sundari, T. T. (2015). Effects of mobile phone use on academic performance of college-going young adults in India. International Journal of Applied Research, 1(9): 898905

Thomée, S., Härenstam, A. \& Hagberg, M. (2011). Mobile phone use and stress, sleep disturbances, and symptoms of depression among young adults - a prospective cohort study. BMC Public Health,31(11), 66.

Young, K.S. \& de Abreu, C.N. (2011). Internet addiction: A handbook and guide to evaluation and treatment. New Jersey, USA: John Wiley \& Sons

Sheila Yu \& Steve Sussman (2020) Does Smartphone Addiction Fall on a Continuum of Addictive Behaviors? Int. J. Environ. Res. Public Health 2020, 17(2), 422; https://doi.org/10.3390/ijerph17020422

Valderrama, J. A. (2014). Development and Validation of The Problematic Smartphone Use Scale. Ph.D. Thesis. Alliant International University, San Francisco. 